\title{
De sediciosos y vándalos: acerca de las representaciones de la protesta policial de diciembre de 2013 en la Argentina
}

\author{
Matías Artese, Jorge Cresto \\ Consejo Nacional de Investigaciones en Ciencia y Técnica (CONICET) e \\ Instituto de Investigaciones Gino Germani (IIGG), Universidad de Buenos Aires

\section{Hernán Tapia, Yésica Signorelli} \\ Universidad de Buenos Aires
}

\section{Resumen}

Recibido: 21 de marzo de 2015.

El 3 de diciembre de 2013 comenzó una serie de protestas policiales en la Argentina mayormente orientadas a obtener mejores condiciones materiales de existencia. Como parte de ese conflicto se registraron saqueos a supermercados y pequeños comercios en distintas ciudades del país. Producto de los enfrentamientos que se registraron durante esos hechos, trece personas murieron y además hubo decenas de heridos y detenidos. Estos episodios incluyeron una serie de posicionamientos ideológicos expuestos mediante una diversidad de discursos provenientes de los manifestantes, los gobiernos provinciales, el Estado nacional y los medios de comunicación, entre otros. En el presente trabajo nos proponemos indagar en las representaciones sobre estos hechos mediante la difusión de declaraciones en dos medios masivos de información: los diarios Clarín y La Nación.

Palabras clave: protesta policial, saqueos, discurso, representaciones, diarios, Argentina

\section{Seditious and vandals: about the representation of the December 2013 police protest in Argentina}

\begin{abstract}
On December 3, 2013, a series of police protests began in Argentina, mostly aimed at improving material conditions. As an offshoot of this conflict, numerous supermarkets and small businesses were looted in different parts of the country. Due to the numerous confrontations recorded during these events, thirteen people died and hundreds were injured or apprehended. These episodes gave rise to numerous ideological positions, exposed in the discourses of protesters, provincial governments, the national government, and the media,
\end{abstract}


among others. This paper looks at the representation of these events through the dissemination of testimonies in two popular media outlets: the newspapers Clarín and La Nación.

Keywords: police protest, looting, discourse, representation, newspapers.

\title{
Sobre sediciosos e vândalos: as representações do protesto policial de dezembro de 2013 na Argentina
}

\begin{abstract}
Resumo
O dia 3 de dezembro de 2013 começou uma série de protestos policiais na Argentina, maiormente orientados a obtenção de melhores condições materiais de existência. Como parte desse conflito, se registraram saques a supermercados e pequenos comércios em distintos pontos do país. Produto dos enfrentamentos que se registraram durante esses fatos, treze pessoas resultaram mortas, além de dezenas de feridos e detidos. Esses episódios incluíram uma série de posicionamentos ideológicos expostos mediante uma diversidade de discursos provenientes dos manifestantes, os governos provinciais, o Estado nacional e os meios de comunicação, entre outros. No presente trabalho nos propomos indagar nas representações sobre esses fatos mediante a difusão de declarações em dois meios de comunicação massivos de informação: os jornais Clarín e La Nación.
\end{abstract}

Palavras chave: protesto policial, saques, discurso, representações, jornais, Argentina.

\section{Introducción}

El período de "fin de año" se ha ido perfilando en Argentina como una etapa de redefiniciones, inflexiones y cambios, que en no pocas ocasiones implica la noción de "época de crisis"; definición construida tanto desde la difusión mediática como de diversos círculos del activismo político. Se trata además de un mes de importantes medidas económicas, en el que se calculan las partidas presupuestarias para el siguiente año, se espera el pago del segundo medio aguinaldo, la aplicación de eventuales bonificaciones en algunas ramas empresariales, además de ser el mes de mayor expectativa de consumo del año. En ese marco, y más aún en períodos de cuestionamiento al gobierno nacional de turno, diversas fracciones sociales y políticas sientan posiciones en el espacio público con el objetivo de dirimir conflictos y definir tendencias en materia de política económica que siempre llevan consigo una carga de significados específicos.

Esta situación de movilizaciones sociales e intrigas políticas de fin de año quizás tenga su quintaesencia en el mes de diciembre de 2001. En aquel momento, el ciclo de protestas terminó en una serie de enfrentamientos que llevaron al fin del gobierno de la Alianza, comandado por Fernando de la Rúa. A la movilización de los sectores 
pauperizados de la sociedad en forma de saqueos, se le sumó la masiva participación de las denominadas "clases medias", que terminaron por condicionar la posterior resolución de la crisis social e institucional (Piva, 2014). Los enfrentamientos acontecidos en todo el país dejaron un saldo de alrededor de cuarenta personas fallecidas y cientos de heridos y detenidos.

En los últimos años, este panorama se ha "revitalizado" por diversas circunstancias. En diciembre de 2012 irrumpieron nuevamente los saqueos de comercios, que comenzaron en la ciudad patagónica de Bariloche y se extendieron a partir de allí a varias ciudades del país. En diciembre de 2013 ocurrieron protestas policiales y posteriores saqueos en varios distritos del país los que protagonizaron el conflicto social. La magnitud de estos hechos dejó el luctuoso saldo de trece personas fallecidas en diversas circunstancias - además de decenas de heridos y detenidos-y la consecuente crisis institucional ${ }^{1}$.

En el presente trabajo proponemos detenernos en este último "gran conflicto" acontecido en el país - la protesta policial de diciembre de 2013 - con la intención de indagar en las representaciones sociales que produjo. Lo haremos tomando como indicadores a las declaraciones difundidas en la prensa gráfica masiva, con para elucidar el modo en que varias personificaciones sociales interpretaron las acciones de conflicto ${ }^{2}$.

Subrayemos que el presente no será un trabajo semiológico ni mucho menos lingüístico: se trata de una investigación sociológica cuya principal intención es verificar qué tipo de enunciados se produjeron y difundieron masivamente en torno de un episodio de conflicto. En tal sentido, vemos a las declaraciones públicas como un campo factible para acceder a la circulación de ideas y representaciones de la realidad y de allí que el estrato empírico para avanzar en nuestros objetivos sean las noticias plasmadas en la prensa escrita, lo que conforma nuestros soportes significantes (Verón, 1987). La propuesta entonces será abordar las declaraciones divulgadas por los diarios Clarín y La Nación entre el 3 y el 15 de diciembre (período que abar-

\footnotetext{
${ }^{1}$ Hacia finales de 2014 comenzaron nuevamente a circular versiones alarmistas sobre la posibilidad de la reiteración de saqueos hacia fin de año producto fundamentalmente de la inflación, por lo cual se ahondó en la necesidad de prevenir hechos vandálicos mediante un refuerzo en la "seguridad". Ver nota "Los super, en alerta para no revivir un caos en diciembre" e "Involucran al Ejército para prevenir saqueos", diario Perfil, días 12 y 27 de octubre de 2014, respectivamente; y "Los comercios chinos insisten en pedir más seguridad para las fiestas", diario Clarín, 21 de noviembre de 2014.

2 Hablamos de personificaciones sociales para referirnos a las relaciones sociales, identidades políticas y/o culturales que adquieren los sujetos en una circunstancia sociohistórica. En el primer prólogo a la edición alemana de El capital, Marx hace referencia a la personificación como la materialización de relaciones económicas en las personas (Marx, 2012, v. 1, p. 8). En nuestro caso, apelamos al término en relación a sujetos que establecen sus identidades y/o roles en un escenario de conflictividad.
} 
ca todo el conflicto) y así intentar conocer los posicionamientos de variada índole (ideológicos, políticos, morales) que adoptaron las personificaciones que participaron directa o indirectamente.

El trabajo se encuentra organizado del siguiente modo: describiremos brevemente los principales acontecimientos que dieron forma a la protesta policial y sus consecuencias. Luego nos introduciremos en la propuesta teórica y metodológica del trabajo y sus lineamientos principales: la vinculación de los hechos de protesta con el aspecto discursivo-ideológico y su difusión masiva. Finalmente, expondremos los resultados obtenidos luego del análisis de datos en base a los sujetos que intervinieron, las principales representaciones difundidas y hacia quiénes fueron dirigidas.

\section{Los principales rasgos del conflicto}

El conflicto en cuestión estuvo conformado principalmente por un alzamiento de las tropas policiales en torno de una demanda laboral-salarial y, en coexistencia con ello, los posteriores saqueos a comercios que se registraron durante la primera quincena de diciembre de 2013 en una gran cantidad de distritos del país.

El inicio de los hechos puede señalarse el 3 de diciembre en Córdoba, segunda provincia argentina en cantidad de habitantes. Allí, un grupo de efectivos pertenecientes al Comando de Acción Preventiva de la policía provincial inició una huelga en reclamo de mejoras salariales y laborales a la que pronto se le sumó una amplia cantidad de efectivos. Más tarde, la casi totalidad de los policías de la capital provincial y de las principales ciudades del interior cordobés se adhirieron a la protesta. De esta manera, la custodia policial se resintió fuertemente en la provincia en un lapso muy corto de tiempo, lo que generó una ausencia de vigilancia en las calles.

En ese contexto, grupos de personas con un heterogéneo grado de organización comenzaron a saquear cientos de comercios de distintos rubros, tanto en distintos puntos de la capital provincial como en los principales centros urbanos del interior cordobés. Estos hechos suscitaron los enfrentamientos entre propietarios de los comercios y sectores de la población ${ }^{3}$, que solo en la provincia de Córdoba dejaron como saldo aproximadamente cien heridos y una persona fallecida.

\footnotetext{
${ }^{3}$ Fueron mayoritariamente reyertas o "linchamientos". Esta forma de enfrentamiento luego cobraría mayor relevancia en los meses de marzo y abril de 2014. Allí los motivos difundidos en medios masivos de información televisiva y gráfica fue el "aumento de la inseguridad y el delito"; aunque nunca existieron pruebas de dicho aumento. La violencia colectiva -y al mismo tiempo anónima- fue difundida así como un acto de indignación justificado, proveniente de "clases medias cansadas de ser víctimas" del delito. Dicha justificación que abrevó en una batería de prejuicios positivos y negativos, dio cuenta de la endeblez del lazo social en determinadas circunstancias y del rol de la manipulación informativa.
} 
Después de un día y medio de huelga, efectivos de la policía provincial y el gobierno de Córdoba finalmente arribaron a un acuerdo, lo que permitió el regreso de la presencia policial a las calles y la recuperación del orden cotidiano, incluyendo el cese de los saqueos a comercios. El resultado fue favorable para los efectivos en cuanto a sus reivindicaciones salariales, aunque hubo decenas de policías imputados y la dirección provincial de la fuerza fue removida.

Pero una vez finalizados los hechos de Córdoba, comenzaron a surgir rápidamente movimientos de protesta "derivados" (Mc Adam, 2002, p. 255) en un proceso en el que se pusieron en marcha "complejos procesos de difusión mediante los cuales las 'lecciones' de ideación, tácticas y organizativas de los tempranos se ponen a disposición de los desafiantes posteriores"4. Es así que hubo manifestaciones en casi todas las provincias de Argentina, a excepción de la ciudad de Buenos Aires y Santa Cruz. El 6 de diciembre se sumaron La Rioja, Catamarca, Neuquén, Río Negro y San Juan. Al día siguiente, se plegaron las policías de Santa Fe y Entre Ríos. El 8 de diciembre comenzó la protesta en la provincia de Buenos Aires - la más poblada del país con aproximadamente 16 millones de habitantes y que posee en correspondencia la fuerza policial más numerosa- y en la provincia de Chaco. A estas le siguieron al día siguiente las protestas en Corrientes, Chubut, Jujuy, Mendoza, Tucumán, Misiones, Tierra del Fuego, San Luis y Formosa. Finalmente, el 11 de diciembre protestaron las policías de Salta, La Pampa y Santiago del Estero. Algunas fueron más breves y otras más extendidas en el tiempo debido a diversos factores.

Tres grandes tipos de demandas se registraron durante las protestas: mejoras en las condiciones salariales y otras reivindicaciones de tipo económico; el derecho a la representación sindical y la no aplicación de sanciones, y mejoras en las condiciones de trabajo. Es decir, se apuntó a conquistar una serie de reivindicaciones de orden económico, mientras que en muy escasas ocasiones se plantearon, al menos abiertamente, reclamos de carácter político. La mayoría de las acciones fueron realizadas por los efectivos policiales; aunque muchas veces estuvieron acompañados por sus familiares, conocidos históricamente como la "familia policial".

Si bien desde un principio se habló de "autoacuartelamiento", la metodología de esta protesta fue principalmente el cese de actividades junto a otros formatos

\footnotetext{
${ }^{4}$ El autor aplica los conceptos de "movimientos iniciadores" y "movimientos derivados" para analizar los ciclos de protesta. Sobre los primeros entiende que, si bien son esporádicos, son los que dan comienzo a un ciclo y por lo tanto son de suma importancia; mientras que los "derivados" son más numerosos, inspirados e impulsados por los primeros. Un movimiento inicial fuerte y exitoso, que logra difundir ciertos elementos e impulsar a otros movimientos, los “derivados", origina así ciclos de protesta.
} 
como manifestaciones públicas, presentación de petitorios, cortes de calle, etc. ${ }^{5}$, instrumentos fundamentales para que los policías consiguieran substanciales mejoras en sus condiciones económicas en los diversos distritos.

Al unísono, los saqueos a comercios se propagaron en casi todos los distritos donde existieron protestas policiales; es decir, donde el control social cotidiano ejercido por esa fuerza se relajó o existió la amenaza de que así podía ocurrir. De este modo, la ausencia de los policías en las calles demostró una gran capacidad de disrupción de la cotidianeidad. Los saqueos tuvieron diverso grado de organización y generaron enfrentamientos que dejaron como saldo la muerte de trece personas en todo el país, además de decenas de heridos y detenidos.

\section{El debate de interpretaciones y la difusión de información}

Como se ha venido desarrollando en otros avances de investigación (Artese et al., 2013; Artese \& Cresto, 2013; Cavalcante, 2009; Coscia, 2009; Farías et al., 2010; Vasilachis de Gialdino, 2005), se verifica una estrecha relación entre: a) acciones colectivas de carácter contencioso, b) producción discursiva de significados concomitantes a esas acciones contenciosas, y c) difusión de esos discursos en medios masivos de información, lo que constituye una "arena" de conflictividad más en el campo discursivo. Se plantea así una "amalgama” entre diversas formas de confrontación, tanto discursivas como no discursivas.

Esta observación implica una discusión teórica que aquí no tendremos espacio de desarrollar, aunque sí creemos necesario subrayar que nos distanciamos de la perspectiva postestructuralista - principalmente la desarrollada por Ernesto Laclau- que presenta como inadecuada la distinción entre prácticas discursivas y no discursivas: si bien dicho autor no niega la existencia de la "realidad material", cuestiona la dicotomía que se suele plantear entre realidad y pensamiento; es decir, "la afirmación de que [los objetos] puedan constituirse como objeto al margen de toda condición discursiva de emergencia” (Laclau \& Mouffe, 2004, p. 147). Para los autores, tanto los hechos materiales como su carácter antagónico y contradictorio se constituyen como tales en el plano del discurso, y de allí que los "significantes vacíos" o flotantes se manifiesten como aquellos conceptos que no están debida-

\footnotetext{
${ }^{5}$ Según los diarios Clarín, La Nación, Página 12, El Ancasti, El Tribuno, El Litoral, Río Negro, Diario de Cuyo, Norte, El diario de La Pampa, La Gaceta, Los Andes, El Territorio y El Sureño. También se recurrió a las siguientes páginas web: TN.com.ar, supernovaformoseña.com.ar e infojusnoticias.gov.ar.
} 
mente significando un acontecimiento determinado, lo que constituyen "lógicas equivalenciales" carentes de sentido (Laclau, 2014, p. 32).

Consideramos, al seguir a Eagleton (2005, p. 279), que esta mirada implica una "inflación del discurso", ya que si prácticas discursivas y no discursivas son indisolubles, no sería posible una solución de continuidad para entender de dónde provienen las ideas sociales. Más aún, y como señala Borón (2000, p. 79), desde aquella perspectiva "las contradicciones del capitalismo se convierten, mediante la prestidigitación 'postmarxista', en simples problemas semánticos. Los fundamentos estructurales del conflicto social se volatilizan en la envolvente melodía del discurso [...], la lucha de clases se convierte en un deplorable malentendu". En tal sentido, consideramos que los discursos en torno al conflicto suponen la expresión de las luchas ideológicas que sí responden a contradicciones y antagonismos del mundo material, y que a su vez los condicionan en cuanto a su producción y difusión. Y es desde esta perspectiva que tomamos a los enunciados como indicadores de la subjetividad de quienes participaron directa o indirectamente de un conflicto, haciendo explícito el campo de disputa ideológico de los enfrentamientos materiales.

Así entendido, el discurso no está al margen sino que es intrínseco a la lucha de clases, entendiendo que la producción y circulación de signos existen en íntima relación con los valores sociales, culturales e ideológicos generados en una comunidad de hablantes (Volóshinov \& Bajtin, 1998). Es decir, el significado de las palabras también se convierte en territorio de disputas que se manifiesta cuando, por ejemplo, se impone un discurso censurador, criminalizador, discriminatorio o que legitima la explotación de clases subordinadas. Por ello consideramos que los enunciados aquí trabajados provienen de sujetos agrupados según las relaciones que establecen política y socialmente, dirigidos a calificar o caracterizar acciones y sujetos. En otras palabras, hablamos de discursos en tanto se trata de texto más su contexto: los roles de los actores intervinientes, su función en las relaciones de producción y sus contradicciones, el lugar político que ocupan, etc. (Raiter, 1999, p. 14); es decir, tener en cuenta el marco ideológico en los que se producen y reproducen socialmente esos discursos (Viana, 2013; Eagleton, 2005).

Aquí nos remitiremos a la difusión de lo que consideramos declaraciones contenciosas, que dan forma al debate de interpretaciones o, dicho en otros términos, a las representaciones sociales del conflicto. Las mismas se producen e intercambian en un proceso comunicativo, y por lo tanto son dinámicas, producto de la interactividad entre sujetos y de su necesidad de explicación de la realidad. Es por ello 
que nos apoyaremos en la idea de que las representaciones sociales se forjan como el producto de los actos del pensamiento de los miembros de una comunidad lingüística - como las opiniones, los significados y los conceptos- que, siendo parte de un entramado de relaciones comunicativas, reproducen simbólicamente una cosa, evento, acción o situación que han percibido y socializado de una manera determinada (van Dijk, 1999; Raiter, 2002; Moscovici, 2003; Castorina \& Kaplan, 2003).

\section{Características del registro de declaraciones}

Como exponente de la escuela del Análisis Crítico del Discurso (ACD), el lingüista Teun van Dijk rescata, de manera multidisciplinaria, diversas herramientas de la sociología, la lingüística y la semiología para el análisis del discurso, las ideologías y representaciones de la realidad en relación con los ejercicios de poder entre grupos en disputa (migratorios, étnicos, de clase, género, etc.). Es esta propuesta la que nos interesa rescatar para adentramos en la revisión de la construcción y circulación de significados y sentidos a través de medios masivos de información, que a su vez conforma un terreno no neutral de comprensión del mundo social.

La utilización de medios gráficos masivos para la exploración de la difusión de discursos contenciosos nos permite acercarnos al conocimiento social que adquiere un conflicto en un momento concreto. Si bien los medios masivos no "provocan" directamente que una forma determinada de interpretar la realidad se imponga como hegemónica, es indudable que "el discurso noticioso es de naturaleza 'estructural': aparte de influir en el importante contenido de nuestros conocimientos y actitudes, lo hace especialmente en las estructuras globales, en las jerarquías de importancia y en los procedimientos de evaluación de la cognición social" (van Dijk, 2007, p. 180). Es por ello que pretendemos revisar las interpretaciones de la protesta a través de las declaraciones publicadas en los dos diarios de mayor tirada nacional (Clarín y La Nación), en los que, además, se expresan mayoritariamente las expresiones de sectores dominantes de la sociedad.

El objetivo no es analizar meramente los discursos mediáticos - en cuyo caso sería pertinente una estrategia exploratoria en más y variados medios - sino examinar las estrategias discursivas de los actores principales del conflicto difundidas en estos medios masivos. Por lo cual ambos diarios, líderes en el mercado de medios de información tanto en soporte papel como digital, adquieren, por su masividad, un lugar de interlocutor legítimo para el acceso cotidiano al conocimiento 
de la agenda pública ${ }^{6}$. Y si bien esa legitimidad no necesariamente implica que se influya de manera monolítica en la conducta del público, sí influye en la manera en que se conoce la realidad (Alvarez Teijeiro et al., 2002). Por ello consideramos que los medios de información masiva constituyen un rol más que importante en la construcción de hegemonía y un campo primordial en la producción y difusión de sentido (Acosta \& Demirdjian, 2013).

La matriz construida para el análisis es de tipo cuanti/cualitativo, sobre la base de la sistematización de noticias en la versión en línea e impresa de los dos diarios mencionados, teniendo como criterio inicial la publicación de algún tipo de caracterización o definición sobre la protesta. Ese criterio lo cumplieron: a) declaraciones explicitas ("entrecomilladas") provenientes de varios sujetos, b) editoriales o notas de opinión con firma de autor, y c) expresiones que en la crónica periodística también dejan ver ciertas calificaciones y caracterizaciones sobre los actores o acciones.

Así, trabajamos sobre un total de 160 noticias, desde la fecha en que se registran los primeros informes del conflicto hasta que estos desaparecen: del 4 al 15 de diciembre de 2013. Sobre la base de esas 160 noticias, registramos 179 declaraciones (30\% surgidas del diario Clarín y 70\% de La Nación). Dentro de cada declaración existieron uno o más nudos conceptuales ${ }^{7}$ que sintetizan una representación o caracterización del hecho de conflicto, conformando un total de 207. Por ejemplo:

'Con gente así nosotros no negociamos. No negociamos porque la actitud está calificada en el Código Penal como delito de sedición. Muchos de los que reclamaban no estaban en actividad. Son sublevados, suspendidos de la fuerza y exonerados', indicó (Sergio Urribarri, gobernador Entre Ríos. La Nación, 9 dic. 2013). Nudo/caracterización: acción sediciosa, ilegal.

El primer ataque se produjo en un local de la cadena Átomo. Luego, desconocidos ingresaron a un comercio de la cadena Changomás, del que intentaron llevarse televisores (periodista de Clarín, 6 dic. 2013). Nudo/caracterización: atacantes, acción bélica.

\footnotetext{
${ }^{6}$ En sus versiones impresas, el diario Clarín es el de mayor tirada en la Argentina. A una distancia importante se ubica en segundo lugar La Nación, pero también con una tirada muy relevante, según datos provistos por el Instituto Verificador de Circulaciones.

${ }^{7}$ Nos referimos a aquellos vocablos significativos que impliquen una definición o caracterización de los hechos o acciones en la estructura de la declaración. Vasilachis de Gialdino (1997) llama nudos a estas ideas centrales de la interpretación: "dentro de una determinada formación discursiva, los vocablos que configuran los nudos de la red semántica están en el núcleo de los modelos interpretativos de la realidad que emplean los hablantes, los que a nivel de la argumentación configuran sus paradigmas argumentativos entendidos como los marcos que delimitan las diferentes formas en que los hablantes representan discursivamente la realidad" (p. 193).
} 
Las declaraciones se tomaron como hechos singulares, por lo que no se registró su replicación en ambos diarios. A grandes rasgos, en un diario se priorizaron las voces de los propios columnistas o periodistas (Clarín), mientras que en el otro se difundieron mayormente la de los comerciantes afectados por los saqueos y los funcionarios de gobierno (La Nación).

Introduciéndonos en el análisis de declaraciones, uno de los objetivos fue indagar en la relación entre los emisores, el tipo de mensajes emitidos y el período en que se realizaron. Veamos en primer lugar cómo fue variando en el tiempo esta distribución.

Gráfico 1. Tema preponderante de la noticia en el que se insertan las declaraciones. $\mathrm{N}=179$

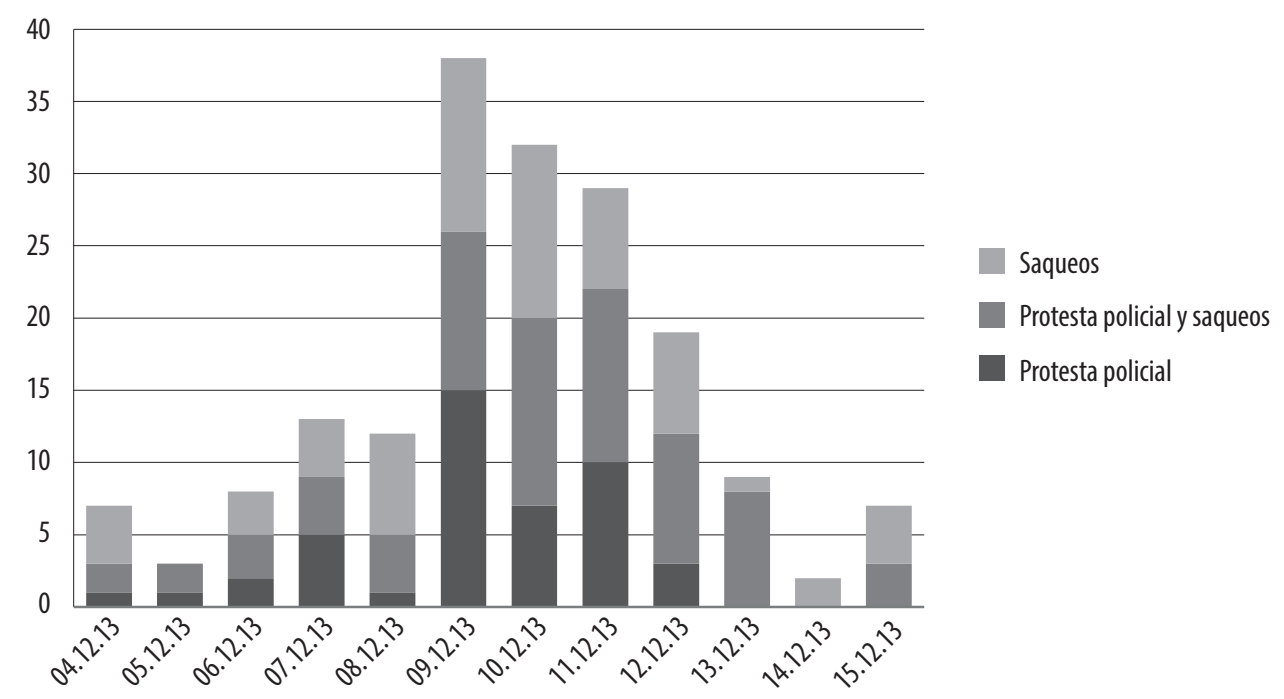

Fuente: elaboración propia sobre la base de noticias de Clarín y La Nación publicadas del 4 al 15 de diciembre de 2013.

En el gráfico 1 podemos apreciar, en primer lugar, la estrecha relación entre la producción de significados y el aumento de la intensidad del conflicto ${ }^{8}$. Esta

\footnotetext{
8 Tengamos en cuenta el surgimiento de protestas — cada una de ellas con diversa duración y desarrollo- a medida que avanza el conflicto: el 3 de diciembre surge la primera en Córdoba; se suman cinco más el día 6; dos más el 7, nueve más el día 9 y las últimas tres el 11 de diciembre.
} 
concomitancia demuestra su pico más alto el 9 de diciembre, seis días después de comenzada la protesta policial y desarrollada a esa altura en 19 provincias. Para ese día, la intervención del gobierno nacional se hizo más notoria, intentando controlar la protesta mediante varias negociaciones urgentes con gobernadores y representantes de las fuerzas.

También se puede observar que los temas preponderantes a los que se refirieron las noticias fueron variando. Las que se refirieron a la protesta policial en exclusividad representaron el 25,1\% de un total de 179 casos. El 39,7\% lo hizo informando sobre la protesta policial y los saqueos en conjunto, mientras que las que se dedicaron exclusivamente a los saqueos representaron un $35,2 \%$.

Salvo los días 7 y 9 de diciembre, las noticias sobre los saqueos - o que los mencionaron- prevalecieron sobre aquellas noticias que se dedicaron exclusivamente a la protesta policial, la cual "desaparece" de las noticias definitivamente a partir del día 13. Es decir que, además de registrarse un aumento notorio en la frecuencia de declaraciones a medida que el conflicto avanza, se perfila una suerte de rotación en el foco de atención: de la protesta policial a los saqueos, probablemente por los enfrentamientos físicos en torno de estos y por los saldos luctuosos que dejaron.

Otro punto a tener en cuenta es la diferencia en la importancia que adquirió el conflicto para los dos diarios trabajados. La Nación publicó más del doble de noticias que Clarín a lo largo del período, pero intervinieron de modo distinto. Ambos coincidieron en el porcentaje de notas dedicado a las protestas policiales (en los dos diarios no supera el 25\% del total). Pero cada diario le dedicó al conflicto un "peso" periodístico diferente: mientras que Clarín le dedicó el 46\% del total de noticias exclusivamente a los saqueos, La Nación lo hizo en un 30\%. Es decir que en el primer caso, la información sobre la protesta policial se desdibuja más fuertemente y la reconstrucción del conflicto pasa sobre todo por sus consecuencias, los saqueos9.

Los sujetos emisores de mensajes en los dos diarios se distribuyen del siguiente modo. De un total de 179 casos analizados, el 37\% fueron producidos por agentes del gobierno nacional. Estas intervenciones no se dieron inmediata-

\footnotetext{
${ }_{9}^{9}$ Es interesante señalar, sin pretender un análisis semiótico, la aparición de ciertas palabras en las tapas de ambos diarios durante el conflicto. De un total de doce días, La Nación mencionó la palabra "saqueo" seis veces, por sobre dos apariciones de las palabras "protesta policial". Por último, tanto en Clarín como en La Nación, la palabra "saqueo" aparece antes que "protesta policial” para definir el conflicto. En esta dirección, Sánchez (2013) señala que en el diario La Nación se publicaron en los últimos 20 años entre una y dos noticias sobre "seguridad" en el $60 \%$ de sus tapas. El diario no comete actos inconexos con la realidad: aunque Buenos Aires está por fuera de las 50 ciudades más violentas del mundo, lidera los índices sobre sensación de inseguridad (p. 136 y ss.).
} 
mente con el inicio de la protesta policial, sino que se difundieron luego de dos días de comenzada la primera protesta en la provincia de Córdoba. Es decir que la necesidad de difundir interpretaciones oficiales sobre los hechos surgió una vez que el conflicto se expandió a nivel nacional, con la consecuente crisis institucional y social desatada. Más adelante veremos cuáles fueron las características principales de esta estrategia.

En segundo lugar, los periodistas y editorialistas de los diarios trabajados intervinieron en la producción de mensajes en un 25\%. Finalmente un 16\% de mensajes provino de políticos opositores. El resto fueron producidos marginalmente por comerciantes y empresarios (7\%), sindicalistas (4\%) y miembros de la iglesia (3\%).

Como mencionamos más arriba, también distinguimos los tópicos hallados en el conjunto de declaraciones contenciosas; es decir, los nudos conceptuales que están dirigidos a caracterizar ideológica, política o moralmente a un grupo determinado de sujetos y a una serie de acciones, sea de modo negativo o positivo. Construimos así seis grupos de caracterizaciones que se distribuyen del siguiente modo (gráf. 2):

Gráfico 2. Tipos de representaciones presentes en las declaraciones. $\mathrm{N}=207$

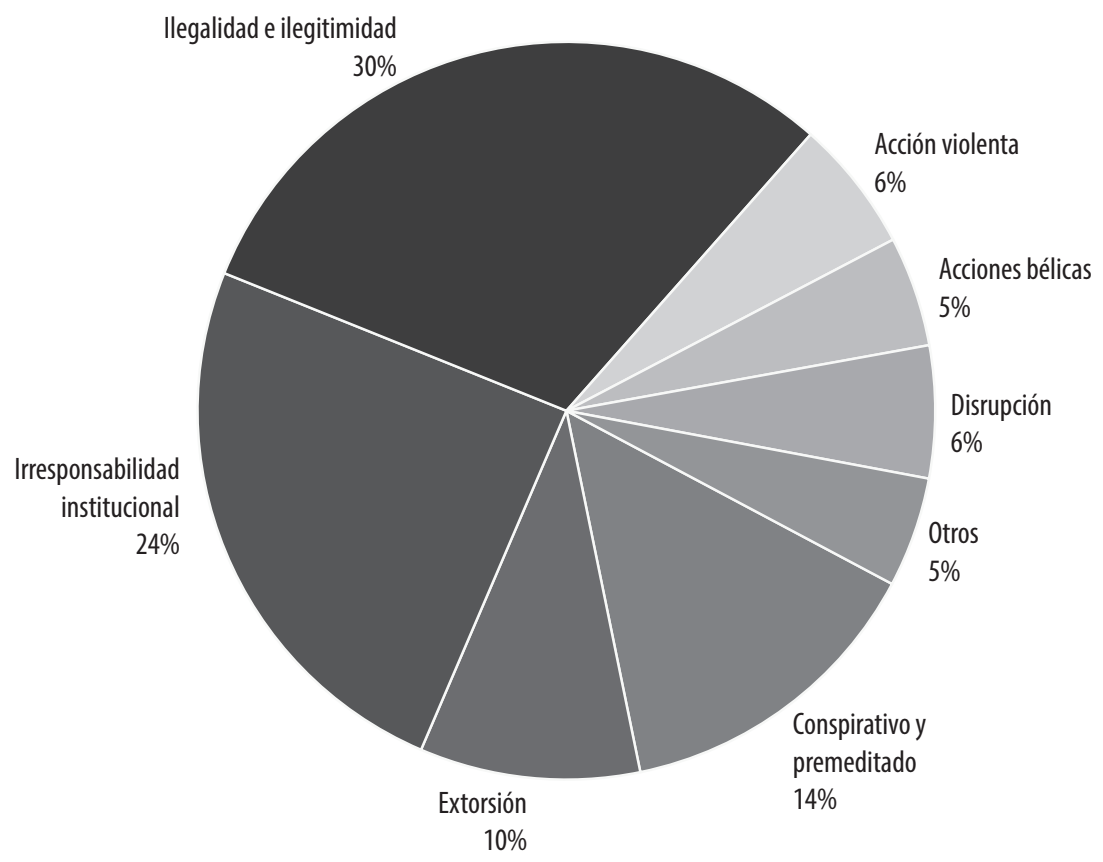

Fuente: elaboración propia sobre la base de noticias de Clarín y La Nación publicadas del 4 al 15 de diciembre de 2013. 
1. Ilegalidad e ilegitimidad. Reúne la mayor cantidad de caracterizaciones en mensajes que contienen las figuras de vandalismo e ilegalidad y otras relativas a acciones al margen de la ley o que pusieran en peligro la propiedad privada o las instituciones. El 33\% de este tipo de calificaciones fue producido por funcionarios del gobierno nacional, dirigidas a las fuerzas policiales y luego también a los hechos de saqueos, en donde el eje estuvo puesto en la acción ilegal e ilegítima de la sedición o la conspiración política. Ejemplo: "el ministro Alak señaló las protestas de las fuerzas de seguridad: 'Van en contra de la ley de las fuerzas, porque la seguridad es un servicio público esencial, que significa que ningún ciudadano puede ser privado de ella" (Julio Alak, ministro de Justicia, Clarín, 9 dic. 2013). Por otra parte, los legisladores opositores y periodistas intervinieron en este tipo de definiciones en un $22 \%$, centrándose en caracterizaciones sobre ilegalidad que apuntaron enteramente a los saqueos ${ }^{10}$. Ejemplo: "El objetivo fue transmitir una consigna muy clara: el que saquea es un ladrón que comete un delito, por eso establecimos un régimen para que las 4.000 cámaras repartidas en los once municipios funcionen como elemento de acumulación de pruebas contra aquellos que hagan intento de saqueos, para luego realizar las denuncias penales", sostuvo Sergio Massa (diputado nacional por el "Frente Renovador", Clarín, 9 dic. 2013).

2. Irresponsabilidad institucional. Se trata de calificaciones que están dirigidas hacia funcionarios del Estado nacional, acusándolos de realizar acciones inconducentes, especuladoras e irresponsables, y hasta como causantes de la crisis. Ese fue el sentido aplicado en la mayoría de declaraciones con este tópico, (39\%) producidas por periodistas y columnistas de los diarios trabajados. En un $25 \%$ lo hicieron los legisladores opositores y en un $18 \%$ lo hicieron los propios funcionarios del gobierno nacional, aunque lógicamente en este caso fue en otra dirección: contra gobiernos provinciales en donde se desenvolvían las crisis. Ejemplo: "Regresó la Cristina de siempre, más crispada, con semblante ajado, distinta a la que pudo observarse por primera vez, tras su convalecencia, con el perrito Simón y el pingüino de peluche. [...] Tuvo que ver, en verdad, con su interpretación de la realidad y de esta difícil coyuntura, observada siempre a través de su mirilla. Cristina aludió a

\footnotetext{
${ }^{10}$ A fines de octubre de 2014 una nueva protesta policial en la provincia de Santa Cruz reavivó este tipo de conceptos desde el seno del Gobierno nacional. El jefe de Gabinete, Jorge Capitanich, señaló nuevamente que los acuartelamientos son un acto delictivo que debe ser penado y que los hechos de diciembre de 2013 constituyeron un intento golpista: "la estrategia urdida por grupos opositores, en donde muchas policías provinciales fueron instrumento el 2 de diciembre del año 2013. En realidad fue una estrategia golpista, de golpe institucional. De afrenta a las instituciones de la República y de la democracia" (Página 12, 31 de octubre de 2014).
} 
sus largas horas de reflexión en Olivos las cuales, sin embargo, no la habrían apartado un ápice de sus argumentaciones políticas remanidas y lineales" (Eduardo van der Kooy, periodista Clarín, 11 dic. 2013).

3. Conspirativo, premeditado. Se trata de caracterizaciones que hablan de grupos de personas que se unen con el único fin de generar algún daño de manera premeditada. El 83\% de estos conceptos fue emitido por funcionarios del gobierno nacional y apuntaron tanto a las fuerzas policiales como a diversos sectores de población involucrados en los saqueos, que habrían estado en connivencia con fracciones de la oposición y las policías con el fin de "generar caos". Ejemplo: "Esta acción alevosa y premeditada con el objeto de atacar el sistema democrático republicano, pretendía que no se pudiera celebrar los 30 años de democracia” (Jorge Capitanich, jefe de Gabinete del gobierno, La Nación, 11 dic. 2013).

4. Hecho extorsivo. En este grupo se encuentran acusaciones y definiciones que consideraron a las personas como dueñas de una actitud chantajista y amenazante, con el fin de obtener un provecho propio, pero que en definitiva genera algún tipo de desestabilización. En este caso fue el gobierno nacional el mayor productor de este tipo de mensajes, con el 75\% del total, y dirigido lógicamente a los integrantes de las fuerzas policiales. Ejemplo: "No entiendo por qué tuvimos que pagar semejante costo por algo que no le encuentro sentido. La extorsión policial no tiene perdón de Dios" (Jorge Alperovich, gobernador provincia de Tucumán, La Nación, 11 dic. 2013).

5. Acciones violentas. Se trata de doce casos con conceptos que remarcan y condenan la carga violenta que tuvieron los acontecimientos, particularmente los saqueos. Más de la mitad de estos comentarios fueron producidos por periodistas y columnistas de los diarios, por una parte, y comerciantes y empresarios afectados por los saqueos, por la otra. Ejemplo: "Durante la madrugada, en Mar del Plata reinó la incertidumbre, el miedo y la violencia por los saqueos contra doce negocios. Ya anoche el transporte público había modificado sus frecuencias" (sin mención, Clarín, 9 dic. 2013).

6. Actos de guerra. Distinguimos a este tipo de calificativos que, si bien implican acciones violentas, tienen la característica de aplicar eufemismos cercanos al universo bélico, como hablar de "atacantes" de "defensa" o incluso "guerra". De las diez declaraciones que encierran estos conceptos, nueve fueron emitidas por periodistas en relación con los saqueos. Ejemplo: "el nuevo día no trajo alivio sino más tensión: la ciudad, literalmente, es 'zona de guerra'. Todas las esquinas están 
valladas, ya sea por una fuerza de seguridad o por la gente que teme una nueva ola de vandalismo" (sin mención, Clarín, 9 dic. 2013).

7. Desviado. En este grupo se encuentran aquellos calificativos con eufemismos que apelaron a ciertas patologías o estadios por fuera de las "conductas normales" ("enfermedad", "locura", "psicosis") ${ }^{11}$ o que remitieron a situaciones emocionales o morales que también son generalmente colocadas por fuera del promedio ("traumático", "insolidario" o "intransigente"). De las doce declaraciones con este tipo de mensajes, cuatro fueron producidas por periodistas, tres por funcionarios del gobierno nacional y dos por miembros de la Iglesia. Fueron dirigidos puntualmente a caracterizar los saqueos y en menor medida la protesta policial, aunque en un caso se habló de "locura represiva", en repudio a la intervención violenta de la Gendarmería en una protesta de familiares de policías ${ }^{12}$. Ejemplo: "Es necesario terminar con la esquizofrenia dual, es necesario que el liderazgo político de cada provincia permita resolver las instancias de negociación" (Jorge Capitanich, jefe de Gabinete del gobierno, La Nación, 9 dic. 2013).

8. Otros. Finalmente aquí reunimos caracterizaciones minoritarias respecto de las últimas (un total de diez, de las cuales seis las produjeron funcionarios del gobierno nacional) y con un contenido muy heterogéneo. Incluimos aquí la única valoración positiva sobre las fuerzas policiales (emitida por el gobernador de la provincia de Buenos Aires, Daniel Scioli) y un caso que habla de instigación ideológica e infiltración en las protestas en apoyo a policías. En este grupo se encuentra también la única denuncia de "linchamiento" que fue publicada en este período: aunque fue una práctica habitual por aquellos días - fundamentalmente como acto de "autodefensa" aplicado desde comerciantes y vecinos saqueados-, los diarios no se hicieron eco de ella salvo en una sola declaración ${ }^{13}$.

Hasta aquí expusimos quiénes intervinieron en la emisión de declaraciones y qué tipo de nudos interpretativos o representaciones del conflicto surgieron. Pero como dijimos más arriba, estas declaraciones contenciosas forman parte del campo ideológico del conflicto y por lo tanto están dirigidas a mellar la identidad

\footnotetext{
${ }^{11}$ Es notable la difusión de esta clase de eufemismos para hechos sociales que, desde ya, tienen causas sociales. Se trata de explicaciones al menos anacrónicas, más propias de épocas de menor desarrollo civilizatorio y menor comprensión de los hechos, en la cual las explicaciones heterónomas tenían raíz en la naturaleza o la biología.

12 Estas caracterizaciones sobre lo normal y lo desviado - o lo legítimo e ilegítimo, dependiendo de los sujetos que movilizasen una protesta - ya han sido exploradas en otros trabajos (Artese et al., 2013 y Coscia, 2009). En el estudio de Coscia, las acciones sindicales tienen un "corrimiento" hacia lo ilegítimo cuando se emparentan con las ideologías de izquierda, generando una "desarmonía" social.

13 "Lo iban a matar y me iban a dar una golpiza tremenda, porque la gente estaba muy violenta, muy sacada, dijo, en diálogo con La Voz". Nota: "Dos historias solidarias en medio del caos", La Nación, 10 de diciembre de 2013.
} 
moral, política o ideológica de diversos sujetos o personificaciones. Veamos entonces qué tipo de representaciones prevalecieron en los sectores a los que fueron dirigidas (gráf. 3).

Como podemos ver, fueron tres las principales personificaciones sociales a las que se apuntó: 1) la población que participó en los saqueos reunió el 39\% del total de caracterizaciones; 2) las diversas policías provinciales en protesta, el 32\%, y 3) finalmente el gobierno nacional con el $18 \%$. En forma mucho más marginal (4\%) se encuentran las caracterizaciones dirigidas a los políticos de la oposición y a las policías provinciales en conjunto. Se trata de declaraciones que formularon una connivencia entre ambos grupos en pos de un "plan desestabilizador", mensaje fuertemente difundido por diversos funcionarios del Ejecutivo nacional. Nos detendremos a partir de aquí en las tres primeras personificaciones a las que fueron dirigidos los mensajes.

a) Contra sectores de la población. Como dijimos, los saqueos fueron concentrando paulatinamente mayor atención en comparación con la protesta policial.

Gráfico 3. Tipos de representación en las declaraciones y hacia quiénes están dirigidas. $\mathrm{N}=207$

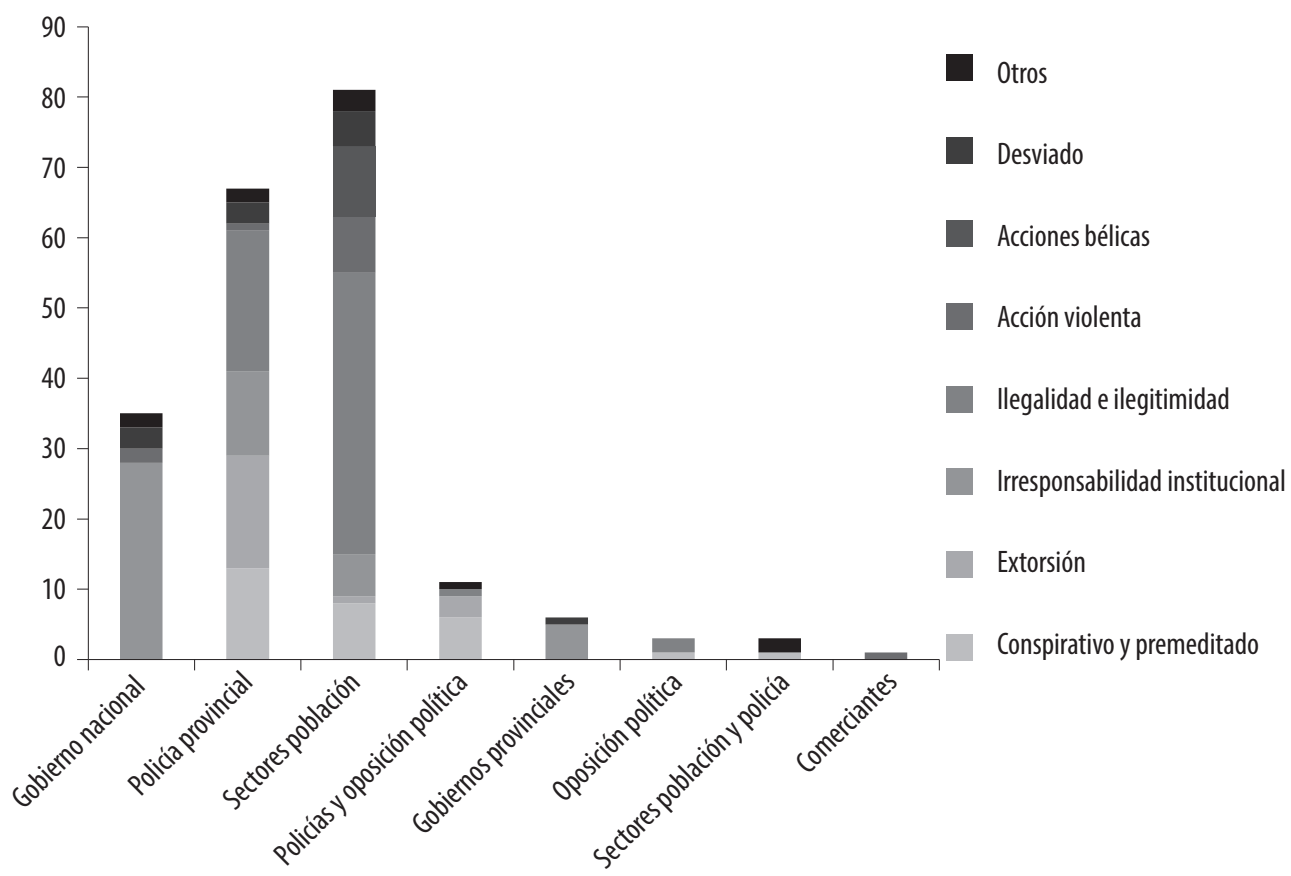

Fuente: elaboración propia sobre la base de noticias de Clarín y La Nación publicadas del 4 al 15 de diciembre de 2013. 
No es de extrañar que los saqueos hayan tomado una mayor relevancia si se tiene en cuenta que, además de las pérdidas materiales, estos hechos fueron gravísimos por el saldo de más de una docena de personas muertas en enfrentamientos. Sin embargo, la difusión sobre estos hechos no giró alrededor de esas graves consecuencias, sino que apuntaron directamente contra la población que protagonizó los hechos con una variedad de caracterizaciones negativas ${ }^{14}$. Lo que nos habla de un tipo de discurso restrictivo (Therborn, 1987, p. 68), es decir, una difusión de términos que se restringen no específicamente a los hechos sino a los sujetos que allí intervinieron. Las caracterizaciones negativas ligaron esas acciones con la marginalidad, la pobreza y la delincuencia, en un esquema de interpretaciones que pertenece a un entramado subjetivo que opera con antelación a este episodio puntual.

En esta clase de mensajes se sintetiza una función en la que los medios masivos cumplen un rol clave: la visión del conflicto como una anomalía que requiere de control inmediato. Es claro que los grupos multimedia modernos tienen un carácter de clase y, por lo tanto, conforman el conjunto de luchas de clases. El reclamo de control no solo se apoya en el requerimiento de la violencia estatal, sino en la difusión de estereotipos de un otro peligroso y en la consecuente ampliación de "consumidores de la industria de la seguridad" (Zaffaroni, 2011, p. 219) que se nutren de este tipo de conceptos más allá de los eventuales episodios de conflicto o protesta social.

En general, este tipo de mensajes provino del gobierno nacional, bajo la conducción de Cristina Fernández de Kirchner, de la oposición política y de los medios gráficos. En el caso del oficialismo, como dijimos, los protagonistas de los saqueos representaron la segunda personificación a la cual destinaron sus mensajes, luego de las policías provinciales. Se los vinculó con la ilegalidad e ilegitimidad pero ligadas fundamentalmente a la idea de acciones conspirativas y premeditadas; es decir que se colocó a los hechos como si fueran "productos artificiales" de una supuesta crisis económica que en realidad no existía. En tal sentido, para el gobierno nacional, las acciones fueron interpretadas como ilegales, pero por ser parte de una supuesta estrategia desestabilizadora.

En cambio, para los periodistas y columnistas de diarios, las fracciones de la población que realizaron estos actos fueron definitivamente el principal blanco

\footnotetext{
${ }^{14}$ La situación se diferencia de lo ocurrido en diciembre de 2001 —último período en el que también los saqueos a comercios se expandieron a gran escala-, pues entonces fueron interpretados como la consecuencia directa y parte de una crisis socioeconómica terminal, antes que el producto de acciones delictivas.
} 
(62\% del total de sus declaraciones), ligando los saqueos con hechos de inseguridad y eufemismos vinculados con significaciones bélicas. También se llegó a vincular a los saqueos con actividades sindicales, uniendo delincuencia, violencia, activismo político y la sensación de miedo que estas fracciones generarían ${ }^{15}$. Desde esta perspectiva, la "vuelta a la cohesión" pretendida desde el discurso mediático - acompañado en buena parte por la oposición política y los representantes empresariales - se centró en la necesidad de mayor control policial, con base en la repentina desprotección de "los sectores medios". De modo que la presencia de diversas fuerzas de seguridad fue entendida como la solución para disolver el estado de desorden, generador de sensaciones de miedo e inseguridad ${ }^{16}$.

b) Contra las policías provinciales. Fueron los protagonistas absolutos en el comienzo del conflicto en la provincia de Córdoba y en menor medida hacia el final. En primer lugar, de 66 mensajes destinados en su contra, 39 (casi el 60\%) los produjo el gobierno nacional. También fueron caracterizados como ilegales e ilegítimos (34\%), principalmente desde funcionarios del gobierno nacional y gobernadores opositores. En segundo lugar, recibieron la caracterización de extorsivos (27\%), es decir, de realizar una acción con el único fin de obtener algún provecho, lo cual también sugiere una acción ilegítima e ilegal. En tercer lugar (22\%), las acciones de las policías provinciales fueron calificadas como conspirativas (o como hechos premeditados, instigados, con voluntad de desestabilización). Por último (20\%) fueron caracterizados como actos de irresponsabilidad, imprudencia y como causantes de la crisis que posteriormente protagonizaron distintas fracciones de la población en los saqueos; es decir, una caracterización que contiene un tono menos crítico en comparación con las anteriores.

c) Contra el gobierno nacional. El 93\% de los mensajes dirigidos a los funcionarios de Gobierno giraron en torno al grado de responsabilidad en la gestión: figuras ligadas a la imprudencia e inoperancia, que acusaban a los funcionarios de ser responsables directos o indirectos del desarrollo de la protesta policial; por ejemplo, por no haber negociado rápidamente con las fuerzas. Estas caracterizaciones nos hablan además de las crisis políticas desatadas en distintas provincias,

\footnotetext{
15 Por ejemplo: "los cordobeses quedaron altamente sensibilizados, en un clima de temor y psicosis ante la eventual repetición de estos episodios. La población teme nuevos hechos de violencia, a partir de las movilizaciones y huelgas lanzadas por gremios estatales (empleados públicos, docentes y judiciales) para exigir idénticas mejoras salariales que las concedidas a la policía" (Orlando Andrada, periodista de La Nación, 8 de diciembre de 2013). ${ }_{16}$ No es novedoso que en el capitalismo actual se instalen estas figuras, que en definitiva responden a interpretaciones dominantes en una sociedad de clases. La teoría del alarmismo social y la sociología del riesgo abordan esta problemática. Ver una introducción a ellas en Acosta \& Demirdjian (2013, p. 118 y ss.).
} 
en una demanda imperante de intervención del Estado nacional por parte de los gobiernos provinciales. Las fuerzas federales no fueron enviadas con la premura que exigieron algunas provincias (en particular Córdoba y Chaco), por lo que se inició una serie de acusaciones mutuas sobre el grado de responsabilidad en la crisis. Es así como el gobierno nacional subrayó que la seguridad es un atributo de cada provincia y que el envío de fuerzas federales en carácter de auxilio no se puede establecer de modo inmediato (las pocas caracterizaciones realizadas sobre los gobiernos provinciales y en particular el de Córdoba van en este sentido).

Las acusaciones sobre irresponsabilidad institucional se emitieron también a raíz de los saqueos que siguieron a la protesta policial (por no enviar fuerzas de seguridad en remplazo de los efectivos en huelga para reprimir el delito). Y por ello es que en este último caso, y a diferencia de la crisis acontecida en diciembre de 2001, las responsabilidades dirigidas al gobierno nacional fueron por no aplicar la fuerza pública de manera eficiente y preventiva.

Por último se registraron otras personificaciones que recibieron distintas representaciones a lo largo del conflicto, pero con valores marginales. Entre ellos los comerciantes, los gobiernos provinciales (principalmente los de Córdoba y Chaco), y la oposición política en conjunto con las policías provinciales, acusadas mancomunadamente de conspiración y desestabilización institucional.

\section{Consideraciones finales}

La protesta policial de diciembre de 2013 adquirió una importancia superlativa por los rápidos e inesperados giros de los acontecimientos. Se tornó un conflicto de suma gravedad por los saldos luctuosos, las pérdidas materiales y las crisis institucionales en que se vieron envueltos tanto los gobiernos provinciales como el nacional.

A medida que la protesta fue superada en notoriedad y magnitud por sus propias derivaciones - la expansión de los actos de saqueos-, también fue aumentando la repercusión en el plano discursivo a través de medios gráficos masivos. De este modo, hemos intentado dar cuenta de las principales representaciones que circularon y ocuparon el período de conflictividad, de lo cual concluimos lo siguiente.

Con respecto de los sujetos intervinientes en la producción de discursos: como vimos, las tres grandes personificaciones que produjeron significados a lo largo del conflicto fueron a) los miembros del gobierno nacional, b) los medios de infor- 
mación masiva y c) políticos y dirigentes opositores. A grandes rasgos podemos decir que el gobierno nacional apeló a representar y difundir el conflicto en general - tanto la demanda salarial de la policía como los saqueos- como una acción conspirativa y extorsiva, es decir, como una serie de sucesos ejecutados a raíz de un plan desestabilizador. Esa fue la dirección adoptada para vincular a la oposición política con fracciones policiales, acusadas de no condenar la protesta ni movilizar recursos para detenerla (en el caso de los gobernadores opositores).

Así, el conflicto fue significado desde una matriz deslegitimadora en la que prevaleció un análisis político de su origen y desarrollo: la intriga y la conspiración en contra del gobierno, en pos de la inestabilidad institucional y la crisis. Por supuesto que desde esta matriz también se negó todo atisbo de autonomía y autenticidad en el conflicto, conceptos que se profundizaron aún más en torno de los saqueos. Estos fueron los rasgos principales de la interpretación por parte del gobierno nacional, sean interpretaciones auténticas o formuladas con la intención de manipular o sesgar políticamente la información ${ }^{17}$. En tal sentido, aunque el conflicto en conjunto incluyó confrontaciones de variado tenor que concentraron el repudio moral desde diversos flancos - sobre todo en relación con los actos de saqueo-, desde el oficialismo se apeló a una comprensión heterónoma del conflicto social, en la que se descartó cualquier posibilidad de legitimidad en los hechos.

En cuanto a la oposición política y a la línea editorial de los diarios analizados, se apuntó a los miembros del gobierno nacional como responsables de la crisis y "desbordados" por ella, tanto en relación con la protesta policial como con los saqueos. De modo que el conflicto sirvió para abrir un nuevo capítulo de acusaciones y disputas entre oficialismo y oposición, sector político que, voluntariamente o no, aunó fuerzas con la corporación mediática.

Con respecto del contenido de los significados: como dijimos, el conflicto comenzó y fue protagonizado por las protestas policiales, pero la atención mediática y de las fuerzas políticas se concentraron alrededor de su derivación: los saqueos, que ante la falta de vigilancia en la vía pública, se extendieron rápidamente. Es así como las caracterizaciones que apuntaron a las fracciones marginales de la población que protagonizaron mayormente estos hechos, abrevaron fundamentalmente en la criminalización.

\footnotetext{
17 Tengamos en cuenta que posteriormente no hubo noticias de investigaciones que pudieran comprobar fehacientemente la hipótesis de la "desestabilización institucional".
} 
Las acciones fueron concebidas como delitos: sea de carácter político desde el gobierno nacional (para lo que se recurrió a la idea de una "operación política" y conspiración en la que no habrían estado ausentes tanto la oposición como las cúpulas policiales para tratar de desestabilizar el orden), o de carácter común, caracterización proveniente de periodistas, editorialistas y/o fracciones de la pequeño-burguesía (cámaras empresariales, comerciantes damnificados, etc.).

Así, las declaraciones - sumadas a la difusión de fotografías sobre acciones de violencia, muchas veces entre pobres-, reavivaron una serie de representaciones que fueron mucho más allá de los actos de enfrentamiento y del conflicto en sí mismo. En momentos precisos de la situación se difundió una serie de conceptos criminalizadores que, junto con un contrapunto basado en la difusión de sensaciones de desconcierto, miedo e incertidumbre, intentaron definir los grupos de "individuos inaceptables" y de justificar las acciones de castigo sobre ellos.

Se conformó así una "pareja" conceptual compuesta por la "difusión de miedo/necesidad de control", a partir de la construcción de un virtual avance e "invasión” de fracciones marginales. Quizás quienes fomentaron con más fuerza este tipo de declaraciones fueron las fracciones de pequeño-burguesía urbana y los periodistas de los diarios trabajados, apelando a un "biotipo" que constituyó el paradigma ideológico de lo negativo, lo extirpable e indeseable en la sociedad.

En tal sentido, no está demás señalar que solo una declaración repudió las reacciones de violencia colectiva por mano propia o de "autodefensa"; mientras que no hubo mención alguna a los trece fallecidos salvo su difusión como dato.

La estrategias discursivas, de este modo, abrevaron en discursos penalizadores, aunque con carácter distinto: por una parte, el oficialismo apuntó a la conspiración política; mientras que en el caso de la oposición y los periodistas de los medios masivos analizados, se apeló a responsabilizar al gobierno nacional por su inoperancia, junto con mensajes de criminalización de los saqueos y reclamos por una mayor intervención del Estado en su aspecto represivo.

Finalmente, consideramos que con esta serie de observaciones y estudios es posible rastrear los indicios de la búsqueda de legitimidad para la aplicación de nuevas y más políticas represivas ${ }^{18}$ y la propagación de ciertos "estados emocio-

\footnotetext{
${ }^{18}$ La provincia de Córdoba, por ejemplo, fue escenario de una profundización de la presencia policial en las calles y de la propagación de las detenciones y contravenciones sobre sujetos que pertenecen a aquel "biotipo" mencionado anteriormente. Situación que se disparó a partir de los hechos aquí analizados. Ver "A un año de los acuartelamientos policiales de Córdoba", Notas: periodismo popular, 3 de diciembre de 2014. Disponible en internet: http://notas.org.ar/2014/12/03/acuartelamientos-policia-cordoba/.
} 
nales"; aunque las razones reales de esos estados no estén directamente vinculadas - al menos de modo comprobable - a las causas que se difunden en forma masiva.

En tal sentido, la intención de este trabajo ha sido tratar de conocer algunos elementos que den cuenta de ciertos procesos sociales (como la ejecución de nuevas políticas de control y represión) que luego pierden, por la velocidad de los acontecimientos, un rastro genealógico.

Queda por seguir indagando en las razones y los rasgos que adquiere la propagación de esta clase de discursos que impulsan la necesidad de mayor control, y que expulsa la noción de autenticidad dentro de la dinámica del conflicto. Y qué tan "naturalizadas" han sido estas representaciones y su grado de expansión en la disputa por configurarse como "representaciones hegemónicas", a través de la receptibilidad que obtienen en distintas fracciones sociales.

\section{Referencias}

Acosta, M. \& Demirdjian, S. (2013). Miedo y medios: la disputa por la hegemonía comunicacional en América Latina. En: Salazar Pérez, R. y Heinrich, M. (coord.). Atrapados por el miedo: medios de comunicación, inseguridad social y militarismo en América Latina (p. 115-130). Buenos Aires: El Aleph.

Alvarez Teijeiro, C., Farré, M. \& Fernández Pedemonte, D. (2002). Medios de comunicación y protesta social en la crisis argentina. Buenos Aires: La Crujía Ediciones.

Artese, M.; Cresto, J.; Gielis, L. \& Barrera, M. (2013). Cuando la protesta fue legítima: un estudio sobre las representaciones del conflicto agrario en 2008 a través del diario La Nación. Buenos Aires: Universidad de Buenos Aires. Facultad de Ciencias Sociales. Instituto de Investigaciones Gino Germani. (Documentos de trabajo; 67).

Artese, M. \& Cresto, J. (2013). El enfrentamiento discursivo en el proceso de autonomización sindical de los trabajadores del Subterráneo de Buenos Aires (2009-2010). Trabajo y Sociedad, 17 (20), p. 205-219.

Borón, A. (2000). Tras el búho de Minerva: mercado contra democracia en el capitalismo de fin de siglo. Buenos Aires: Fondo de Cultura Económica.

Cavalcante, C. (2009). Piqueteros: algunos limites político-ideológicos para a constitução de un movimento unificado [sic]. Buenos Aires: Programa de Investigación sobre el Movimiento de la Sociedad Argentina (PIMSA) (Documento de trabajo; 73). Disponible en: http://www.pimsa.secyt. gov.ar/publicaciones/DT\%2073.pdf

Castorina, J. \& Kaplan, C. (2003). Representaciones sociales: problemas teóricos y desafíos educativos. En: Castorina, J. (comp.). Representaciones sociales, problemas teóricos y conocimientos infantiles (p. 9-27). Barcelona: Gedisa.

Coscia, V. (2009). ¿Entre el diálogo y la confrontación?: luchas sindicales desde una perspectiva comunicacional. Lavboratorio, 23, p. 8-24.

Eagleton, T. (2005). Ideología. Barcelona: Paidós.

Farías, A.; Nardin, S. \& Santana, G. (2010). El lado oscuro de la protesta, representaciones en eclipse: un análisis de las noticias del diario Clarín, 2008-2009. En: VI Jornadas de Sociología de la Universidad Nacional de La Plata. Facultad de Humanidades y Ciencias de la Educación, 9 y 10 de diciembre de 2010. 
Laclau, E. (2014). Los fundamentos retóricos de la sociedad. Buenos Aires: Fondo de Cultura Económica.

Laclau, E. \& Mouffe, Ch. (2004). Hegemonía y estrategia socialista: hacia una radicalización de la democracia. Buenos Aires: Fondo de Cultura Económica.

Marx, K. (2012). El capital. Buenos Aires: Siglo XXI.

Mc Adam, D. (2002). Movimientos "iniciadores" y "derivados": procesos de difusión en los ciclos de protesta. En: Traugott, M. (comp.). Protesta social (p. 243-269). Barcelona: Edit. Hacer.

Moscovici, S. (2003). La conciencia social y su historia. En: Castorina, J. A. (ed.). Representaciones sociales, problemas teóricos y conocimientos infantiles. (p. 91-110). Barcelona: Gedisa.

Piva, A. (2014). La movilización antikirchnerista de "clase media": entre la crisis de representación y la recomposición neo populista del consenso. Astrolabio, 12, p. 394-421.

Raiter, A. (1999). Discurso y ciencia social. Buenos Aires: Editorial Universitaria de Buenos Aires (EUDEBA).

Raiter, A. (2002). Representaciones sociales. En: Raiter, A. (ed.). Representaciones sociales (p. 11-29). Buenos Aires: Editorial Universitaria de Buenos Aires (EUDEBA).

Sánchez, R. (2013). Medios de comunicación y violencia criminal en la Argentina:la agenda de la seguridad en el diario La Nación. En: Salazar Pérez, R. \& Heinrich, M. (coords.). Atrapados por el miedo: medios de comunicación, inseguridad social y militarismo en América Latina (p. 131-153). Buenos Aires: Elaleph.

Therborn, G. (1987). La ideología del poder y el poder de la ideología. Madrid: Siglo XXI.

Van Dijk, T. (1999). Ideología. Barcelona: Gedisa.

Van Dijk, T. (2007). Estructuras y funciones del discurso. México: Siglo XXI.

Vasilachis de Gialdino, I. (1997). Discurso político y prensa escrita: la construcción de representaciones sociales. Barcelona: Gedisa.

Vasilachis de Gialdino, I. (2005). La representación discursiva de los conflictos sociales en la prensa escrita. Estudios Sociológicos, 23 (67), p. 95-137.

Viana, N. (2013). As representações da violência no discurso jornalístico. Comunicação \& Política, 31 (2), p. 37-56.

Verón, E. (1987). La palabra adversativa. En: Verón, A. et al. (ed). El discurso político: lenguajes y acontecimientos. Buenos Aires: Hachette.

Volóshinov, V. \& Bajtin, M. (1998). ¿Qué es el lenguaje? Buenos Aires: Almagesto.

Zaffaroni, E. (2011). La cuestión criminal. Buenos Aires: Planeta.

\section{Contactos}

\section{Matías Artese}

Instituto de Investigaciones Gino Germani, Universidad de Buenos Aires

mat_artese@hotmail.com

\section{Jorge Cresto}

Facultad de Ciencias Sociales, Universidad de Buenos Aires

jorge_cresto@hotmail.com

\section{Hernán Tapia}

Facultad de Ciencias Sociales, Universidad de Buenos Aires

hp.tapia@hotmail.com

\section{Yésica Signorelli}

Facultad de Ciencias Sociales, Universidad de Buenos Aires

yesicasignorelli@hotmail.com 